\title{
Synthesis, Crystal Structures and Magnetic Properties of Mononuclear High-Spin Cobalt(II) Complex
}

\author{
Mohd. Muddassir ${ }^{1}$ and You Song ${ }^{2, *}$ \\ 1 Department of Chemistry, College of Science, King Saud University, Riyadh 11451, Saudi Arabia; \\ muddassirchem@gmail.com \\ 2 State Key Lab of Coordination Chemistry, Nanjing National Laboratory of Microstructures and School of \\ Chemistry and Chemical Engineering, Nanjing University, Nanjing 210023, China \\ * Correspondence: yousong@nju.edu.cn
}

Received: 14 January 2020; Accepted: 29 January 2020; Published: 4 February 2020

check for updates

\begin{abstract}
A new four-coordinated high-spin Co(II) complex was synthesized through the reactions of $\mathrm{Co}(\mathrm{NSC})_{2}$ with bathocuproine, by the diffusion method, resulting in an infinite one-dimension chain. Both static and dynamic magnetic properties were measured. The magnetic properties investigation shows that the single $\mathrm{CO}^{\mathrm{II}}$ ion properties dominate the magnetic behavior in the complex. Despite the presence of a four-coordinated single $\mathrm{Co}^{\mathrm{II}}$ ion, no SMM properties were exhibited by the complex.
\end{abstract}

Keywords: X-ray crystallography; cobalt complex; H-bonding; magnetism

\section{Introduction}

The analysis of several multinuclear different metal systems that show a slow relaxation of magnetization and magnetic hysteresis below the blocking temperature (TB), without undergoing 3D magnetic ordering, has paramount importance in the area of molecular magnetism that depends upon coordination complexes. One prominent example is iron oxide-based materials that exhibit huge magnetocrystalline anisotropy, high Curie temperature, relatively large magnetization and also have excellent chemical stability and corrosion resistivity as reported by Trukhanov et al. [1-8]. These nanomagnets, called SMMs [9], are extremely important for magnetic information storage and quantum computing [10-13]. The beginning of the SMM behavior is the presence of an energy barrier (U) for the inversion of the molecular magnetization, which allows the molecule to hold its magnetization after removing an applied field. Since the first publication of slow magnetic relaxation in double-decker bis(phthalocyaninato)terbium(III) [14] and dysprosium(III) [15] complexes, only a few examples of mononuclear first-row transition metal complexes have been reported exhibiting SMM behavior [16-22]. Examples are four- and five-coordinate complexes such as trigonalpyramidal Fe(II) $[16,18,19]$, tetrahedral Co(II) [20,21], and squarepyramidal Co(II) [22]. In these few examples of mononuclear SMMs from the first-row transition ions, the low coordination number seems to be necessary to minimize the ligand field relative to the spin-orbit coupling, enabling the desired slow magnetic relaxation effects to be observed as polynuclear SMMs [9].

Currently, more research is focused on mononuclear based SMMs due to the increased size, which can be used in quantum computing devices from an application point of view. The drawback of multinuclear metal complexes is that they have small anisotropies despite their larger size, which encourages researchers to obtain new SMMs on the basis of mononuclear complexes having a large ground state. The most promising way to use the anisotropy of $\mathrm{Co}(\mathrm{II})$ complex to form is to regulate the addition of a metal ion that results from the formation of a mononuclear Co(II) complex, for potential applications in magnetism. 
Keeping all these things in mind, we decided to synthesize a tetrahedral Co(II) complex through mixing $\mathrm{Co}(\mathrm{NSC})_{2}$ with bathocuproine, by diffusion method. We chose isothiocyanate ligands because of their ability to increase the structural modulation of the magnetic features as well as occupy a single coordination site since they are linear and thus bring flexibility to the overall structure. The complex was characterized by elemental analysis, IR spectroscopy and single-crystal XRD. The variable temperature magnetic measurements were done, while the TGA was measured in a nitrogen environment.

\section{Experimental Procedures}

\subsection{Physical Measurements}

The IR spectra were recorded with a VECTOR 22 spectrometer using KBr pellets in the $200-4000 \mathrm{~cm}^{-1}$ region. Elemental analyses of C, H and N were performed on a PerkinElmer $240 \mathrm{C}$ elemental analyzer. The data of magnetic properties for crystalline samples were collected on a Quantum Design MPMP-XL 7 superconducting quantum interference device (SQUID) magnetometer. Corrections of magnetic susceptibilities were carried out considering both the sample holder as the background and the diamagnetism of the constituent atoms estimated from Pascal's constant.

\subsection{Starting Materials}

Chemicals and solvents were purchased from commercial sources as analytical reagents and used without further purification.

\subsection{Synthesis}

$\left.[\mathrm{Co} \text { (bathocup)(NCS) })_{2}\right](1)$

Complex 1 was synthesized by the method of slow interlayer diffusion in a test tube. A solution of Co(NCS $)_{2}(4.4 \mathrm{mg}, 0.025 \mathrm{mmol})$ dissolved in $1 \mathrm{~mL}$ of water was added to the bottom of a test tube, and a mixture of methanol and water $(3.0 \mathrm{~mL}, 2: 1(\mathrm{v} / \mathrm{v}))$ was added carefully along the tube wall as the interlayer, and then a solution of bathocuproine $(18.0 \mathrm{mg}, 0.05 \mathrm{mmol})$ in $1.0 \mathrm{~mL}$ of methanol was gently added as the top layer. The tube was sealed and left in the dark for two weeks; the X-ray quality crystals as green-colored needle-shaped of $\mathbf{1}$ were afforded in a reasonable yield. Yield: $63 \%$. Elemental analysis calc for $\mathrm{C}_{26} \mathrm{H}_{16} \mathrm{~N}_{4} \mathrm{~S}_{2} \mathrm{Co}(\%)$ : C, 61.53; H, 3.18; N, 11.04. Found: $\mathrm{C}, 62.09 ; \mathrm{H}, 3.30 ; \mathrm{N}, 10.77$.

\subsection{X-ray Structure Determination}

The diffraction data were collected with a Siemens (Bruker) SMART CCD diffractometer using monochromatic Mo-K $\alpha$ radiation $(\lambda=0.71073 \AA)$ at $291 \mathrm{~K}$. Data reduction and cell refinement were performed using SAINT-Plus [23], and the space group was determined from systematic absences by XPREP and further justified by the refinement results.

The structure was solved by direct methods and refined by full-matrix least rectangulars on $F^{2}$ using the SHELXL-97 program package [24,25]. Absorption corrections were carried out using the SADABS program supplied by Bruker [26]. All non-hydrogen atoms were located in difference (different) Fourier maps and refined anisotropically. The hydrogen atoms were added geometrically and refined isotropically with fixed $U$ values using a riding model, which are tied 1.2 or 1.5 times to the parent atoms. Details of the crystallographic data collection, structural determination and refinement are summarized in Table 1. Selected bond distances and angles for complex $\mathbf{1}$ are shown in Table 2. Calculations concerning the molecular geometry, the affirmation of chosen space groups and the analysis of hydrogen bonds were performed with PLATON [27]. The molecular graphics were done with MERCURY (Version 4.3) [28]. Data can also be obtained free of charge in cif format by request from The Cambridge Crystallographic Data Centre at www.ccdc.cam.ac.uk/data_request/cif. 
Table 1. Crystal structural data and refinement parameters for complex $\mathbf{1}$.

\begin{tabular}{|c|c|}
\hline CCDC No. & 1449385 \\
\hline Formula & $\mathrm{C}_{28} \mathrm{H}_{16} \mathrm{~N}_{4} \mathrm{~S}_{2} \mathrm{Co}$ \\
\hline Formula weight & 507.50 \\
\hline Temperature/K & 296.15 \\
\hline Crystal system & monoclinic \\
\hline Space group & $P 2_{1} / c$ \\
\hline$a / \AA$ & $14.7201(16)$ \\
\hline$b / \AA$ & $20.906(2)$ \\
\hline$c / \AA$ & $8.2020(9)$ \\
\hline$\alpha /^{\circ}$ & 90.00 \\
\hline$\beta /^{\circ}$ & $101.847(2)$ \\
\hline$\gamma /^{\circ}$ & 90.00 \\
\hline Volume/ $\AA^{3}$ & $2470.3(5)$ \\
\hline Z & 4 \\
\hline$\rho_{\text {calc }} / \mathrm{mg} \mathrm{mm}^{-3}$ & 1.578 \\
\hline$\mu / \mathrm{mm}^{-1}$ & 6.473 \\
\hline$F(000)$ & 1108 \\
\hline $2 \theta$ range for data collection & 1.4 to $27.5^{\circ}$ \\
\hline & $-19 \leq \mathrm{h} \leq 16$ \\
\hline Index ranges & $-26 \leq \mathrm{k} \leq 27$ \\
\hline & $-10 \leq 1 \leq 10$ \\
\hline Reflections collected & 17,032 \\
\hline Independent reflections & $5783[R(\mathrm{int})=0.034]$ \\
\hline Data/restraints/parameters & $5783 / 0 / 298$ \\
\hline Goodness-of-fit on $F^{2}$ & 1.05 \\
\hline Final $R$ indexes $[I>2 \sigma(I)]$ & $R_{1}{ }^{a}=0.127, \mathrm{w} R_{2}^{b}=0.408$ \\
\hline Largest diff. peak/hole/e $\AA^{-3}$ & $5.00 /-0.70$ \\
\hline
\end{tabular}

Table 2. Selected bond distances $(\AA)$ and angles (deg) for complex 1 .

\begin{tabular}{cccc}
\hline \multicolumn{5}{c}{ Complex 1 } \\
\hline Co1-N1 & $1.896(6)$ & N3-Co1-N4 & $81.8(2)$ \\
\hline Co1-N2 & $1.940(7)$ & C22-N2-Co1 & $176.3(7)$ \\
\hline Co1-N3 & $2.032(5)$ & C7-N4-Co1 & $112.5(4)$ \\
\hline Co1-N4 & $2.043(5)$ & C9-N4-Co1 & $128.6(4)$ \\
\hline N1-Co1-N2 & $109.3(3)$ & C2-N3-C6 & $118.8(5)$ \\
\hline N1-Co1-N3 & $122.9(3)$ & C2-N3-Co1 & $128.7(4)$ \\
\hline N2-Co1-N3 & $108.1(3)$ & C6-N3-Co1 & $112.4(4)$ \\
\hline N1-Co1-N4 & $122.5(3)$ & C24-N1-Co1 & $170.0(7)$ \\
\hline N2-Co1-N4 & $109.3(2)$ & & \\
\hline
\end{tabular}

\section{Results and Discussion}

For complex 1, the reaction was done in a molar ratio of 1:1 between $\mathrm{Co}^{\mathrm{II}}(\mathrm{NCS})_{2}$ and bathocuproine, and resulted in the formation of green-colored needle-shaped products. Complex $\mathbf{1}$ was stable towards air and moisture. 


\subsection{Structure Description}

\section{Crystal Structures of Complex 1}

The structure based on single-crystal X-ray studies is shown in Figure 1. Details for the crystallographic data collection are given in Table 1. Selected bond lengths and angles are summarized in Table 2. The structure was a neutral mononuclear complex as depicted in Figure 1. The Co atom in the complex 1 had a four-coordinate $\mathrm{CoN}_{4}$ tetrahedral environment wherein the two thiocyanate groups in cis positions and two nitrogen atoms from the bathocuproine ligand completed the coordination sphere (Figure 1). The $\mathrm{Co}-\mathrm{N}_{\text {thiocyanate }}$ bond distances (average 1.918(6) $\AA$ ) were rather shorter than the two nitrogen atoms from the bathocuproine ligand $\mathrm{Co}-\mathrm{N}_{\text {bathocuproine }}$ bond distances (average 2.038(3) $\AA$ ), which are an example of high-spin $\mathrm{Co}^{\mathrm{II}}$ ions. These bond distances can be considered as normal as reported by others [29]. Although the $\mathrm{N}-\mathrm{Co}-\mathrm{N}$ bond angle involving the two cis thiocyanate groups $\left(109.3(3)^{\circ}\right)$ was less bent than that involving the bathocuproine ligand (81.8 (2)), both of them deviated from the angle for an ideal octahedron $\left(90^{\circ}\right)$ and played a dominant role in stabilizing the molecule. Each unit of complex 1 was isolated from each other, and the shortest intermolecular $\mathrm{Co}-\mathrm{Co}$ distance was 8.247(1) $\AA$, and therefore no close intermolecular exchange pathways were apparent in the structure. This distance was almost comparable with the similar mononuclear Co(II) complex having Co $\cdots$ Co distance $\sim 8.593 \AA$, exhibiting slow magnetic relaxation $[20,22]$. Bond lengths and angles within the bathocuproine group were in agreement with those reported for the free bathocuproine molecule [29]. The thiocyanate ligands were nearly linear (the value of the $\mathrm{N}-\mathrm{C}-\mathrm{S}$ angle was 178.58). The common S-C and C-N distances of 1.598 and $1.153 \AA$ in the complex 1 point out a partial $\pi$-delocalization alongside the metal-thiocyanate bonds. This remark is consistent with the observation that the SCN-ligand is polarizable without difficulty. The availability of large substituted groups such as phenyl and methyl inhibited stacking in a way that the phenanthroline cores eclipsed each other. The complex 1 units were connected to each other through $\pi-\pi$ interaction through the sulfur of one of the thiocyanates and one of the nitrogens from the bathocuproine unit, giving rise to an infinite one-dimension chain (Figure 2).

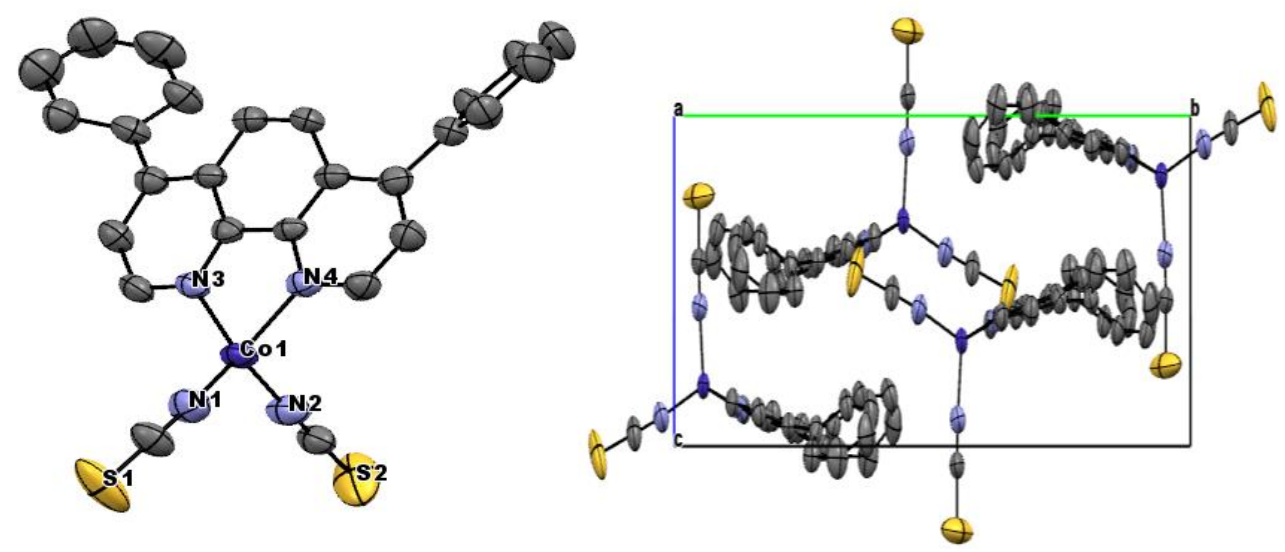

Figure 1. Crystal structure diagram of complex 1 and packing arrangement. 


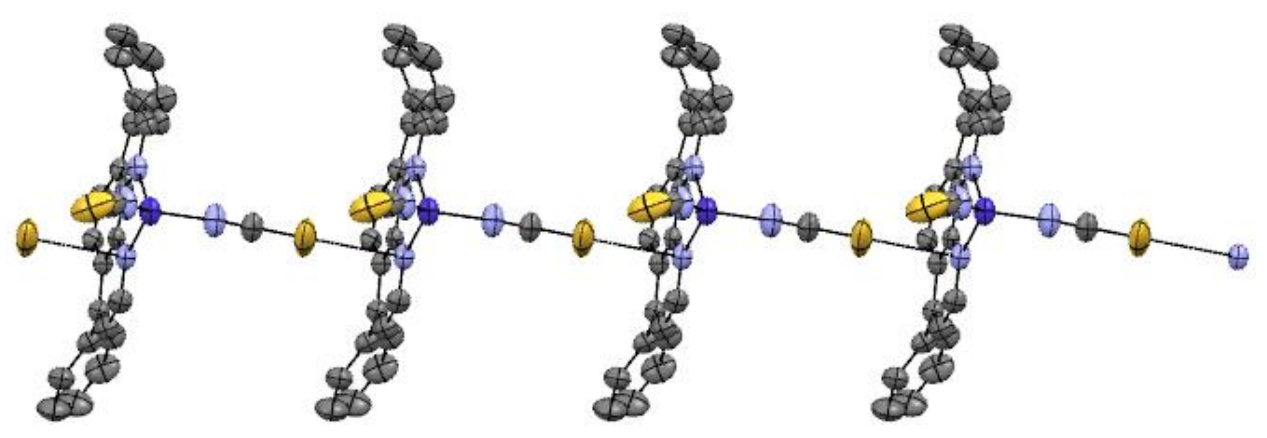

Figure 2. $\pi-\pi$ interaction in complex 1 leading to one-dimension chain.

\subsection{FT-IR Spectra}

The thiocyanate group stretching frequency represents plentiful knowledge about the nature of the ligand and its coordination modes $[30,31]$. The $v(\mathrm{CN})$ value was used to determine the thiocyanate coordination mode. If the value was $\sim 2050 \mathrm{~cm}^{-1}$, then nitrogen bonded, while greater than $\sim 2100 \mathrm{~cm}^{-1}$ implied the sulpher complex bonded with thiocyanate group. The $v(\mathrm{CN})$ band was found at 2071 $\mathrm{cm}^{-1}$ and is indicative of nitrogen coordination in complex 1 rather than sulphur coordination to $\mathrm{Co}$ (II) ion (terminal N-bonded) [32]. Bands related to the phen ligand were observed at 1638, 1592, 1541 and $1511 \mathrm{~cm}^{-1}$, as reported by others [33,34]. Similar bands were found at lower frequencies in free ligand. A very sharp intensity band at $704 \mathrm{~cm}^{-1}$ was attributed to the characteristic signatures of aromatic ring vibration. The complex formation was also revealed by the low-intensity bands observed at $446-417 \mathrm{~cm}^{-1}$ indicative to coordination bonds of $\mathrm{Co}-\mathrm{N}$, according to the literature [30].

\subsection{Thermogravimetric Analysis}

Thermogravimetric analysis of the crystalline material of complex $\mathbf{1}$ was carried out to study the pyrolysis pattern in temperature range $25-700{ }^{\circ} \mathrm{C}$ as shown in Figure 3 , and the weight loss occurred in two steps. The noticeable weight loss in the temperature range from 40 to $377^{\circ} \mathrm{C}$ indicated the removal of one of the thiocyanate group (weight loss observed $=11.39 \%$; calculated $11.43 \%$ ). The second step between 378 and $670{ }^{\circ} \mathrm{C}$ corresponded to the loss of one of the benzene rings attached to bathocuproine and one remaining thiocyanate group (weight loss observed $=24.75 \%$; calculated $=26.6 \%$ ).

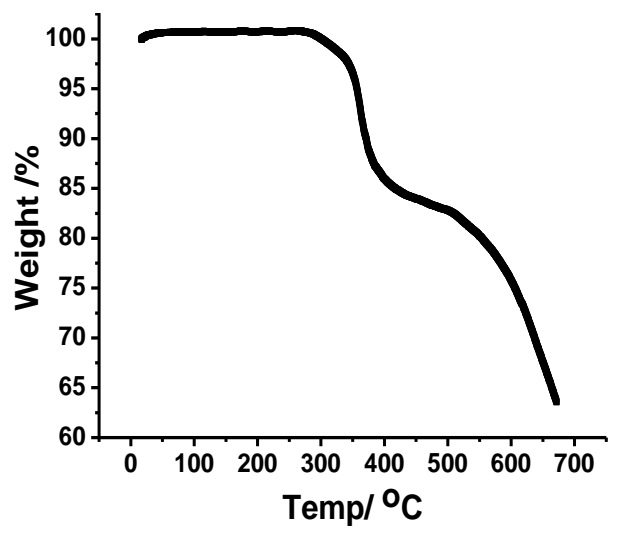

Figure 3. TGA curves of complex 1.

FT-IR and thermogravimetric analysis indicate the formation of complex $\mathbf{1}$, thus proving that the original crystalline material has the same identity as the single crystals used to solve the structure of the complexes. 


\subsection{Magnetic Properties}

\subsubsection{Magnetic Property of Complex $\mathbf{1}$}

The magnetic properties of complex 1 are depicted in Figure 4. At room temperature, $\chi_{\mathrm{M}} T$ was $1.93 \mathrm{~cm}^{3} \cdot \mathrm{K} \cdot \mathrm{mol}^{-1}$, in close agreement with a spin quadruplet with small unquenched angular momentum [35-39]. At lower temperatures, $\chi_{M} T$ gradually decreased until $60 \mathrm{~K}$, and then it dropped significantly to a value of $0.71 \mathrm{emu} \mathrm{mol}^{-1} \mathrm{~K}$ at $1.8 \mathrm{~K}$. It was because of local anisotropy of the $\mathrm{Co}^{2+}$ ion supported by the spin-orbit coupling rather than intermolecular interactions due to the absence of any close Co $\cdots$ Co contacts.

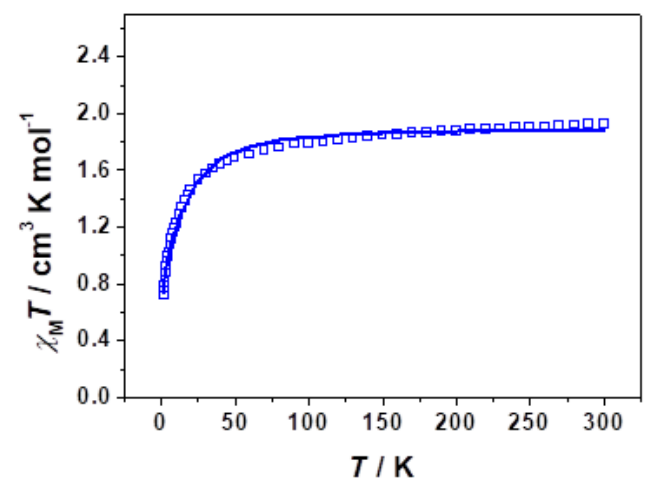

Figure 4. Temperature dependence of the $\chi_{M} T$ product for complex 1 under an applied field of 100 Oe.

Considering the spin-orbit coupling contribution, the magnetic properties can be elaborated by the Hamiltonian (Equation (1)) with the occurrence of an axial crystal zero-field splitting $D$ and $S=3 / 2$.

$$
\hat{H}=D\left[\hat{S}_{z}^{2}-(1 / 3) S(S+1)\right]+g \beta H \hat{S}
$$

Furthermore, the deduced expressions are as follows:

$$
\begin{gathered}
\chi_{\|}=\frac{N g_{C_{0}}^{2} \mu_{B}^{2}}{k T} \frac{1+9 e^{-2 D / k_{B} T}}{4\left(1+e^{-2 D / k_{B} T}\right)} \\
\chi_{\perp}=\frac{N g_{C_{0}}^{2} \mu_{B}^{2}}{k T} \frac{4+\frac{3 k_{B} T}{D}\left(1-e^{-2 D / k_{B} T}\right)}{4\left(1+e^{-2 D / k_{B} T}\right)} \\
\chi_{C_{0}}=\left(\chi_{\|}+2 \chi_{\perp}\right) / 3
\end{gathered}
$$

When the mean-field correction is taken into account, the best fits of complex 1 give $g=2.010(3)$, $D=25(1) \mathrm{cm}^{-1}$ and $z j^{\prime}=-0.48(2) \mathrm{cm}^{-1}$ (mean-field correction) with $R=8 \times 10^{-4}$, which is comparable with the reported $D$ value in four-coordinated $\mathrm{Co}^{\mathrm{II}}$ complexes [40]. The weak intermolecular magnetic interaction can be attributed to the weak contact from SCN to the neighboring $\mathrm{Co}^{\mathrm{II}}$ ion via $\mathrm{S}$ atom, which becomes a bridge mediating magnetic interaction.

\subsubsection{AC Susceptibility of Complex 1}

Due to the large uniaxial anisotropy [41], some four-coordinated Co ${ }^{\mathrm{II}}$ complexes show the SMM behavior. To understand the dynamics of magnetization, the AC magnetic measurements for complex 1 were done in zero applied dc field and 5 Oe oscillating at $997 \mathrm{~Hz}$, demonstrating that $\chi^{\prime}$ increases continually below $4 \mathrm{~K}$, yet no peaks were visible at low temperatures (Figure 5). No out-of-phase susceptibility signals were observed above $1.8 \mathrm{~K}$, despite the presence of four-coordinated single $\mathrm{Co}^{\mathrm{II}}$ ion (Figure 6). This suggests that the $D$ value is not large enough in complex $\mathbf{1}$ for the requirement of SMM, which is probably quenched by the very weak intermolecular interaction. 


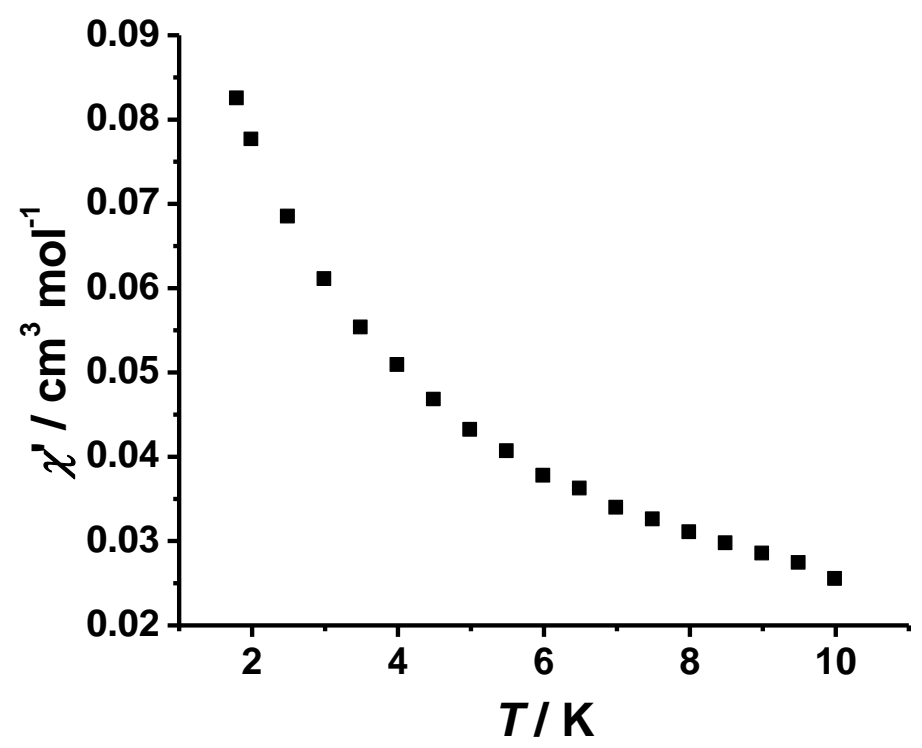

Figure 5. Variable-temperature AC magnetic susceptibilities (in-phase) of complex $\mathbf{1}$ in an AC field of 5 Oe with a constant frequency of $997 \mathrm{~Hz}$.

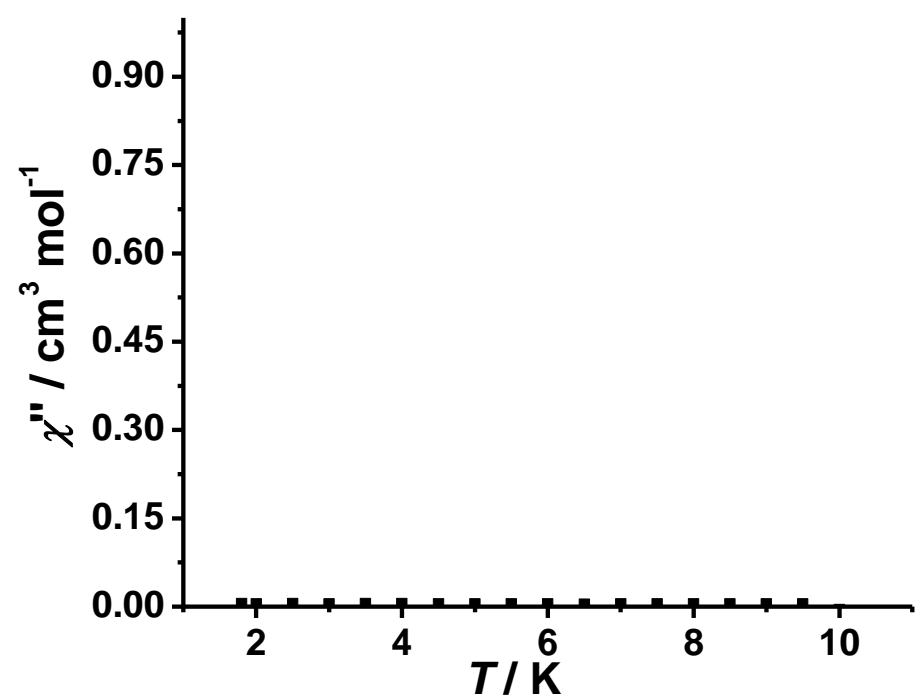

Figure 6. Variable-temperature AC magnetic susceptibilities (out-of-phase) of complex $\mathbf{1}$ in an AC field of 5 Oe with a constant frequency of $997 \mathrm{~Hz}$.

\section{Conclusions}

A new tetra-coordinated high-spin $\mathrm{Co}^{\mathrm{II}}$ complex was prepared by mixing $\mathrm{Co}(\mathrm{NCS})_{2}$ with bathocuproine resulting in tetrahedral $\left.\left[\mathrm{Co}^{\mathrm{II}} \text { (bathocup)(NCS }\right)_{2}\right](\mathbf{1})$ by the diffusion method and was thoroughly characterized. Complex 1 connected to each other through $\pi-\pi$ interactions through the sulfur of one of the thiocyanates and one of the nitrogens from the bathocuproine ligand, leading to an infinite one-dimension chain. The investigation of the magnetic properties reveals that the single $\mathrm{Co}^{\mathrm{II}}$ ion properties dominate the magnetic behavior in complex 1 . However, no single-molecule magnetic properties were observed in complex 1 despite the presence of four-coordinated single $\mathrm{Co}^{\mathrm{II}}$ ion. Nonetheless, experiments involving similar types of complexes using more distortion, different coordination spheres, geometries and ligand fields are in progress in our laboratories to get fascinating magnetic properties. 
Author Contributions: M.M. and Y.S.; methodology, Y.S.; validation, M.M. and Y.S.; formal analysis, M.M.; investigation, M.M. and Y.S.; data curation, M.M.; writing—original draft preparation, M.M. and Y.S.; writing-review and editing, Y.S.; visualization, M.M.; funding acquisition. All authors have read and agreed to the published version of the manuscript.

Acknowledgments: We are grateful to Researchers Supporting Project number (RSP-2019/141), King Saud University, Riyadh, Saudi Arabia for financial assistance.

Conflicts of Interest: The authors declare that they have no known competing financial interests.

\section{References}

1. Turchenko, V.; Trukhanov, A.; Trukhanov, S.; Balasoiu, M.; Lupu, N. Correlation of crystalline and magnetic structures of barium ferrites with dual ferroic properties. J. Magn. Magn. Mater. 2019, 477, 9-16. [CrossRef]

2. Trukhanov, S.V.; Troyanchuk, I.O.; Trukhanov, A.V.; Fita, I.M.; Vasil'ev, A.N.; Maignan, A.; Szymczak, H. Magnetic properties of La0.70Sr0.30MnO2.85 anion-deficient manganite under hydrostatic pressure. JETP Lett. 2006, 83, 33-36. [CrossRef]

3. Turchenko, V.; Kostishyn, V.G.; Trukhanov, S.; Damay, F.; Porcher, F.; Balasoiu, M.; Lupu, N.; Bozzo, B.; Fina, I.; Trukhanov, A.; et al. Crystal and magnetic structures, magnetic and ferroelectric properties of strontium ferrite partially substituted with in ions. J. Alloys Compd. 2020, 821, 153412. [CrossRef]

4. Vinnik, D.A.; Podgornov, F.V.; Zabeivorota, N.S.; Trofimov, E.A.; Zhivulin, V.E.; Chernukha, A.S.; Gavrilyak, M.V.; Gudkova, S.A.; Zherebtsov, D.A.; Ryabov, A.V.; et al. Effect of treatment conditions on structure and magnetodielectric properties of barium hexaferrites. J. Magn. Magn. Mater. 2020, 498, 166190. [CrossRef]

5. Trukhanov, S.V.; Trukhanov, A.V.; Turchenko, V.A.; Kostishin, V.G.; Panina, L.V.; Kazakevich, I.S.; Balagurov, A.M. Crystal structure and magnetic properties of the BaFe12-xInxO19 (x=0.1-1.2) solid solutions. J. Magn. Magn. Mater. 2016, 417, 130-136. [CrossRef]

6. Trukhanov, S.V.; Trukhanov, A.V.; Kostishyn, V.G.; Panina, L.V.; Turchenko, V.A.; Kazakevich, I.S.; Trukhanov, A.V.; Trukhanova, E.L.; Natarov, V.O.; Balagurov, A.M. Thermal evolution of exchange interactions in lightly doped barium hexaferrites. J. Magn. Magn. Mater. 2017, 426, 554-562. [CrossRef]

7. Trukhanov, S.V.; Trukhanov, A.V.; Kostishyn, V.G.; Panina, L.V.; Trukhanov, A.V.; Turchenko, V.A.; Tishkevich, D.I.; Trukhanova, E.L.; Oleynik, V.V.; Yakovenko, O.S.; et al. Magnetic, dielectric and microwave properties of the BaFe12-xGaxO19 (x $\leq 1.2)$ solid solutions at room temperature. J. Magn. Magn. Mater. 2017, 442, 300-310. [CrossRef]

8. Trukhanov, A.V.; Trukhanov, S.V.; Kostishyn, V.G.; Panina, L.V.; Korovushkin, V.V.; Turchenko, V.A.; Vinnik, D.A.; Yakovenko, E.S.; Zagorodnii, V.V.; Launetz, V.L.; et al. Correlation of the atomic structure, magnetic properties and microwave characteristics in substituted hexagonal ferrites. J. Magn. Magn. Mater. 2018, 462, 127-135. [CrossRef]

9. Gatteschi, D.; Sessoli, R.; Villain, J. Molecular Nanomagnets; Oxford University Press: Oxford, UK, 2006; ISBN 9780198567530.

10. Wernsdorfer, W.; Sessoli, R. Quantum Phase Interference and Parity Effects in Magnetic Molecular Clusters. Science 1999, 284, 133-135. [CrossRef]

11. Leuenberger, M.N.; Loss, D. Quantum computing in molecular magnets. Nature 2001, 410, 789-793. [CrossRef]

12. Meier, F.; Loss, D. Coherent spin quantum dynamics in antiferromagnetic rings. Phys. B Condens. Matter 2003, 329-333, 1140-1141. [CrossRef]

13. Bogani, L.; Wernsdorfer, W. Molecular spintronics using single-molecule magnets. Nat. Mater. 2008, 7 , 179-186. [CrossRef] [PubMed]

14. Ishikawa, N.; Sugita, M.; Ishikawa, T.; Koshihara, S.; Kaizu, Y. Lanthanide Double-Decker Complexes Functioning as Magnets at the Single-Molecular Level. J. Am. Chem. Soc. 2003, 125, 8694-8695. [CrossRef]

15. Ishikawa, N.; Sugita, M.; Ishikawa, T.; Koshihara, S.; Kaizu, Y. Mononuclear Lanthanide Complexes with a Long Magnetization Relaxation Time at High Temperatures: A New Category of Magnets at the Single-Molecular Level. J. Phys. Chem. B 2004, 108, 11265-11271. [CrossRef]

16. Freedman, D.E.; Harman, W.H.; Harris, T.D.; Long, G.J.; Chang, C.J.; Long, J.R. Slow Magnetic Relaxation in a High-Spin Iron(II) Complex. J. Am. Chem. Soc. 2010, 132, 1224-1225. [CrossRef] 
17. Harman, W.H.; Harris, T.D.; Freedman, D.E.; Fong, H.; Chang, A.; Rinehart, J.D.; Ozarowski, A.; Sougrati, M.T.; Grandjean, F.; Long, G.J.; et al. Slow Magnetic Relaxation in a Family of Trigonal Pyramidal Iron(II) Pyrrolide Complexes. J. Am. Chem. Soc. 2010, 132, 18115-18126. [CrossRef]

18. Weismann, D.; Sun, Y.; Lan, Y.; Wolmershäuser, G.; Powell, A.K.; Sitzmann, H. High-Spin Cyclopentadienyl Complexes: A Single-Molecule Magnet Based on the Aryl-Iron(II) Cyclopentadienyl Type. Chem.—A Eur. J. 2011, 17, 4700-4704. [CrossRef]

19. Lin, P.-H.; Smythe, N.C.; Gorelsky, S.I.; Maguire, S.; Henson, N.J.; Korobkov, I.; Scott, B.L.; Gordon, J.C.; Baker, R.T.; Murugesu, M. Importance of Out-of-State Spin-Orbit Coupling for Slow Magnetic Relaxation in Mononuclear FeII Complexes. J. Am. Chem. Soc. 2011, 133, 15806-15809. [CrossRef]

20. Zadrozny, J.M.; Long, J.R. Slow Magnetic Relaxation at Zero Field in the Tetrahedral Complex [Co(SPh)4]2-. J. Am. Chem. Soc. 2011, 133, 20732-20734. [CrossRef]

21. Jurca, T.; Farghal, A.; Lin, P.-H.; Korobkov, I.; Murugesu, M.; Richeson, D.S. Single-Molecule Magnet Behavior with a Single Metal Center Enhanced through Peripheral Ligand Modifications. J. Am. Chem. Soc. 2011, 133, 15814-15817. [CrossRef]

22. Zadrozny, J.M.; Liu, J.; Piro, N.A.; Chang, C.J.; Hill, S.; Long, J.R. Slow magnetic relaxation in a pseudotetrahedral cobalt(ii) complex with easy-plane anisotropy. Chem. Commun. 2012, 48, 3927-3929. [CrossRef]

23. Bruker. APEX3; Bruker AXS Inc.: Madison, WI, USA, 2016.

24. SHELXTL Suite of Programs, Version 6.14, Bruker Advanced X-ray Solutions; Bruker AXS Inc.: Madison, WI, USA, 2000-2003.

25. Sheldrick, G.M. A short history of SHELX. Acta Crystallogr. A 2008, 64, 112-122. [CrossRef] [PubMed]

26. Sheldrick, G.M. Crystal structure refinement with SHELXL. Acta Crystallogr. Sect. C Struct. Chem. 2015, 71, 3-8. [CrossRef]

27. Spek, A.L. Single-crystal structure validation with the program $\{\backslash$ it PLATON\}. J. Appl. Crystallogr. 2003, 36, 7-13. [CrossRef]

28. Macrae, C.F.; Edgington, P.R.; McCabe, P.; Pidcock, E.; Shields, G.P.; Taylor, R.; Towler, M.; van de Streek, J. Mercury: Visualization and analysis of crystal structures. J. Appl. Crystallogr. 2006, 39, 453-457. [CrossRef]

29. Smolko, L.; Černák, J.; Dušek, M.; Titiš, J.; Boča, R. Tetracoordinate Co(ii) complexes containing bathocuproine and single molecule magnetism. New J. Chem. 2016, 40, 6593-6598. [CrossRef]

30. Nakamoto, K. Infrared and Raman Spectra of Inorganic and Coordination Compounds; Wiley: New York, NY, USA, 1986; ISBN 04710106699780471010661.

31. Golub, A.M.; Kohler, H.; Skopenko, V.V. Chemistry of Pseudohalides; Elsevier: Amsterdam, The Netherlands, 1986; ISBN 044499534X 9780444995346.

32. Baer, C.; Pike, J. Infrared Spectroscopic Analysis of Linkage Isomerism in Metal-Thiocyanate Complexes. J. Chem. Educ. 2010, 87, 724-726. [CrossRef]

33. Vázquez-Vuelvas, O.F.; Hernández-Madrigal, J.V.; Gaviño, R.; Tlenkopatchev, M.A.; Morales-Morales, D.; Germán-Acacio, J.M.; Gomez-Sandoval, Z.; Garcias-Morales, C.; Ariza-Castolo, A.; Pineda-Contreras, A. X-ray, DFT, FTIR and NMR structural study of 2,3-dihydro-2-(R-phenylacylidene)-1,3,3-trimethyl-1H-indole. J. Mol. Struct. 2011, 987, 106-118. [CrossRef]

34. Clarke, R.C.; Latham, K.; Rix, C.J.; Hobday, M. Heterocyclic Amine Derivatives of Zinc Organophosphonates. Chem. Mater. 2004, 16, 2463-2470. [CrossRef]

35. Mateescu, A.; Raptopoulou, C.P.; Terzis, A.; Tangoulis, V.; Salifoglou, A. pH-Specific Synthesis and Structural and Spectroscopic Characterization of a Complex between CoII and N,N-Bis(phosphonomethyl)glycine: Cobalt-Phosphonate Interactions in the Solid State and in Solution. Eur. J. Inorg. Chem. 2006, 2006, 1945-1956. [CrossRef]

36. Jankovics, H.; Daskalakis, M.; Raptopoulou, C.P.; Terzis, A.; Tangoulis, V.; Giapintzakis, J.; Kiss, T.; Salifoglou, A. Synthesis and Structural and Spectroscopic Characterization of a Complex between Co(II) and Imino-bis(methylphosphonic acid): Gaining Insight into Biologically Relevant Metal-Ion Phosphonate Interactions or Looking at a New Co(II)-Organophosphonate Materi. Inorg. Chem. 2002, 41, 3366-3374. [CrossRef] [PubMed] 
37. Matzapetakis, M.; Dakanali, M.; Raptopoulou, C.P.; Tangoulis, V.; Terzis, A.; Moon, N.; Giapintzakis, J.; Salifoglou, A. Synthesis, spectroscopic, and structural characterization of the first aqueous cobalt(II)-citrate complex: Toward a potentially bioavailable form of cobalt in biologically relevant fluids. JBIC J. Biol. Inorg. Chem. 2000, 5, 469-474. [CrossRef] [PubMed]

38. Rizzi, A.C.; Brondino, C.D.; Calvo, R.; Baggio, R.; Garland, M.T.; Rapp, R.E. Structure and Magnetic Properties of Layered High-Spin Co(II)(1-threonine)2(H2O)2. Inorg. Chem. 2003, 42, 4409-4416. [CrossRef] [PubMed]

39. Rodriguez, A.; Sakiyama, H.; Masciocchi, N.; Galli, S.; Gálvez, N.; Lloret, F.; Colacio, E. Hexacyanocobaltate(III) Anions as Precursors of Co(II)-Ni(II) Cyano-Bridged Multidimensional Assemblies: Hydrothermal Syntheses, Crystal and Powder X-ray Structures, and Magnetic Properties. Inorg. Chem. 2005, 44, 8399-8406. [CrossRef]

40. Idešicová, M.; Titiš, J.; Krzystek, J.; Boča, R. Zero-Field Splitting in Pseudotetrahedral Co(II) Complexes: A Magnetic, High-Frequency and -Field EPR, and Computational Study. Inorg. Chem. 2013, 52, 9409-9417. [CrossRef]

41. Yang, F.; Zhou, Q.; Zhang, Y.; Zeng, G.; Li, G.; Shi, Z.; Wang, B.; Feng, S. Inspiration from old molecules: Field-induced slow magnetic relaxation in three air-stable tetrahedral cobalt(ii) compounds. Chem. Commun. 2013, 49, 5289-5291. [CrossRef]

(C) 2020 by the authors. Licensee MDPI, Basel, Switzerland. This article is an open access article distributed under the terms and conditions of the Creative Commons Attribution (CC BY) license (http://creativecommons.org/licenses/by/4.0/). 